\title{
Perspective, Cartography and Dynamic Notions: From the Plane Bozzetto to Solid Perspective in Two Examples in Tuscany
}

\author{
Nevena Radojević ${ }^{1}$
}

Published online: 12 May 2016

(C) Kim Williams Books, Turin 2016

\begin{abstract}
In order to create a perspective drawing on a curved surface, the quadraturista had to face, in addition to the flat perspective drawing issues, also the ones related to the mapping of the three dimensional surface. In literature we can find two methodologically different approaches related to the flat design transposition procedures onto the curved surface: indirect and direct method. The indirect one, partially described by Vignola, is based on the use of pre-designed cartoons on the ground. The direct one, described by Andrea Pozzo, is based on the direct projection of a flat grid onto the curved surface. Both the ceiling painting of the Church of San Matteo in Pisa and the parietal one of the Church of S. Caterina in Livorno show, even if observed from the privileged viewpoints, some irregularities. These irregularities, as we are going to show, are actually the consequences of the method applied for the transposition of the flat drawings onto the curved surfaces.
\end{abstract}

Keywords Linear perspective - Architectural perspective · Quadraturismo · Illusionistic painting on the vault surface $\cdot 3 \mathrm{~d}$ survey $\cdot$ Panoramic imaging · Three-dimensional restitution · Cartography · Surface development · Bozzetto $\cdot$ Field of view - Geometry

\section{Introduction}

In order to create a perspective drawing on a curved surface (both parietal and ceiling), the artist needs to face, in addition to the linear perspective construction issues, also the ones related to the mapping of the three-dimensional surface. The transposition of the flat preparatory perspective drawing or bozzetto onto the vault

Nevena Radojević

nevena.radojevic@gmail.com

1 Dipartimento di Architettura, DiDA, via della Mattonaia, 14, 50121 Florence, Italy 
surface is always done with the aid of the grid or quadrettatura. Once the deformed grid is obtained on the curved surface, the preparatory drawing should only be fitted into that grid.

Both the ceiling painting of the Church of San Matteo in Pisa and the parietal painting of the Church of Santa Caterina in Livorno show some drawing deformations, even if seen from the privileged viewpoints. These irregularities, as we are going to show, are consequences of the method applied for the transposition of the flat drawings onto the curved surfaces. The transposition method, in both examples, is not based on exact projective principles, or more precisely, the mapping of the vault (by the aid of central projection of the flat grid) does not occur directly on the actual vault, but on a scaled and simplified model. The mapping procedure of the actual vault, instead, comprises the design transposition onto the vault from the developed, actual size cartoons (done by enlargement of the scale ones).

In literature we can find two methodologically different approaches related to grid transformation procedures that we could define as the indirect and direct methods. In his famous treatise Perspectiva pictorum et architectorum, Andrea Pozzo explained the method he used for the transposition of the flat drawing onto the vaulted surface in the Church of St. Ignatius in Rome, that consists of a direct central projection from the privileged viewpoint ${ }^{1}$ of the grid placed onto the vault impost onto the vault. By applying this direct method the eventual drawing deformations produced by the irregularities of the surface itself would not be visible in the painting when seen from the privileged viewpoint, as Pozzo also observed (Pozzo 1693). Another method, the indirect one, is given by Jacopo Barozzi da Vignola and is based on the use of pre-designed cartoons on the ground (Vignola 1583; Troili 1672; Bibiena 1711).

Vaulted surfaces, as we know from practice, are never perfectly regular. ${ }^{2}$ If the transposition method of the straight lines is direct from the viewpoint onto the surface, the irregularities of the vault donot influence the final visual result, whilst if the method is indirect (by the aid of cartoons for instance) these irregularities become evident on the painting and visible even from the privileged viewpoint. Real scale drawings that need to be transferred onto the vaults are done, according to the indirect method, by the enlargement of the cartoons designed by the aid of scaled models. These scaled models never perfectly correspond to the real surfaces and the discrepancy between the two different geometries produces errors.

Another issue is the uniqueness of the viewpoint for which the paintings were intended. As seen in some other examples, the viewpoint was not necessarily always intended to be static by painters, especially when the picture plane (quadro) is vertical and the observer is free to move along it (Bartoli 2015). However, as far as we are concerned, this argument was never discussed in literature.

\footnotetext{
1 The "privileged viewpoint" or just a "viewpoint" is the center of projection of an imaginary spatial configuration onto the surface. The depicted illusory space appears as it should when seen from this point.

2 The vaults are rarely regular geometries as the literature usually describes them. Their form is a result of the complex constructive processes.
} 


\section{Two Ways of Transposing Flat Drawings onto the Curved Surfaces}

In his treatise Le due Regole della Prospettiva pratica in the paragraph "Del modo di fare le prospettive nei palchi, e nelle volte, che si veggono di sotto in su" Vignola outlines how to depict perspective drawing onto concave vaults (Vignola 1583, p. 86). The method consists of the realization of one quarter of the cartoon that needs to be transferred onto the surface. However, he did not give any cartoon realization method, and he only said that it is similar to the one that he described for the façades ${ }^{3}$ (Vignola 1583 , p. 89). He observed that the very convenient fact, in making the cartoons, is that the artist does not need to rise above the scaffolds; he can draw all the lines that he needs staying comfortably on the ground ${ }^{4}$ (Vignola 1583, p. 87).

In his comments to Vignola's method, Danti gave a detailed explanation of how to find the foreshortenings of the vertical elements on the vault surface. The method consists of the direct projection of the points that we need onto the scaled model (or scaled section of the vault): once we have measured the curvature of the vault, we need to design the scaled profile onto the cartoon, then draw the elements that we intend to represent in the same scale (columns for instance) and find the intersections between the vault contour and the visual rays that converge towards the viewpoint ${ }^{5}$ (Vignola 1583, p. 89).

In the described manner we are able to find the position of the horizontal longitudinal lines onto the vault surface. These lines, which transform in lines onto the vault, remain straight also in the developed projection (in the case of a barrel vault). The horizontal transversal lines, which transform in ellipses onto the vault, are complex curves in developed projection. In order to trace them we also need their point's positions in longitudinal section. Therefore, the description of the method given by Danti is not exhaustive, because it does not say anything about the way in which we can find those positions. As Vignola also said, the described methods for the realization of the perspective drawing onto concave vaults created a lot of confusion, and the best way to understand them is in practice.

He also observed that this method can produce certain errors when the vaults are irregular and the sections are not all the same. Therefore, in order to correct eventual errors, he suggested placing the leveled horizontal wire onto the vault impost and transiting it from the privileged viewpoint. If the line designed onto the surface (by the aid of the cartoon) diverges from this alignment it should be corrected (in order to appear straight when seen from the privileged viewpoint). For the vertically depicted elements (columns for example) he gives a very interesting method that consists of placing the vertical wire fixed in the projection of the viewpoint onto the

\footnotetext{
${ }^{3}$ This method is not exhaustive because the façades are flat surfaces.

${ }^{4}$... che nel fare li cartoni... è commodissima cosa il fargli in terra nel pavimento, per non avere a salire sopra $i$ ponti, e potere con $i$ fili tirare tutte le linee che ci bisognono,... e il simile diciamo nel fare $i$ cartoni delle volte ... (Vignola 1583, p. 87).

5 ... La onde quando ci sarà proposta la volta per farvi la prospettiva, bisogna primieramente pigliare la circonferenza del suo sesto con una centina, e segnarla nel cartone, e poi mettervi appresso le grandezze perfette delle cose, che si vogliono disegnare nella volta, e tirando da esse linee rette fino al punto della distanza, si segnarano nell'arco della volta le intersegationi, che le prefate linee ci danno ... (Vignola 1583, p. 89).
} 
vault. This wire represents the intersection of all vertical projective plans. The next step would be the alignment of this wire, perhaps with the projection of the corresponding flat drawing of the vertical elements on the ground (Mele et al. 2015).

The second method for the transposition of the flat drawing onto the vault surface is one given by Andrea Pozzo in his treatise Perspectiva pictorum et architectorum and, as we mentioned, it consists in the direct projection of the real scaled grid, placed on the vault impost, onto the vault surface by the aid of wires fixed in the viewpoint (Pozzo 1693, Fig. 100a). The wire that is fixed in the viewpoint is mobile and by moving it along the fixed grid we are able to design the grid's central projection directly onto the vault surface. This projection corresponds to the grid shadow that the candle placed in the viewpoint would trace onto the vault. Once we have a deformed grid, the flat perspective drawing (bozzetto) should only be fitted into it. By applying this (or similar) method, based on direct projection onto the real vault, any geometrical irregularities of the surface would not produce any visible deformations in the painting when seen from the same viewpoint, as Pozzo also observed (Pozzo 1693). This method is similar to the second one suggested by Vignola for the corrections of the errors that would be eventually produced by applying his own first method (cartoons).

The two case studies that we are going to analyze in this paper are both examples of the same transposition method, only partially described by Vignola but surely well known in practice.

\section{Case Study One: Church of San Matteo in Pisa}

In the quadratura painted onto the vaulted ceiling surface in the Church of San Matteo in Pisa (fresco by Giuseppe and Francesco Melani between 1717 and 1718) some irregularities are evident even at the first sight. Neither the depicted column's bases nor the depicted cornices are parallel to the real ones. The cornices below the painted balconies and above their balustrades have a pretty strange shape. They seem to be neither circular nor elliptical and not even parallel to each other. The vertical lines in the drawing (perpendicular to the picture plane) appear curved in some points while they should look straight when seen from the privileged viewpoint (Figs. 1, 2).

These characteristics were analyzed on the metric data basis provided by the integrated survey campaign (photogrammetry and laser scanner) in order to answer some questions such as:

- What is the procedure that one has to follow in order to make a flat preparation drawing for such an irregular floor plane (trapezial)?

- Is it possible to follow a similar procedure to the one used for rectangular basis (that considers only a quarter of the detailed drawing due to the symmetry) and deform parts afterwards; or are all the particulars to be designed for the whole floor plan?

- Which is the operational procedure for the transposition of the flat drawing onto the vaulted surface? 


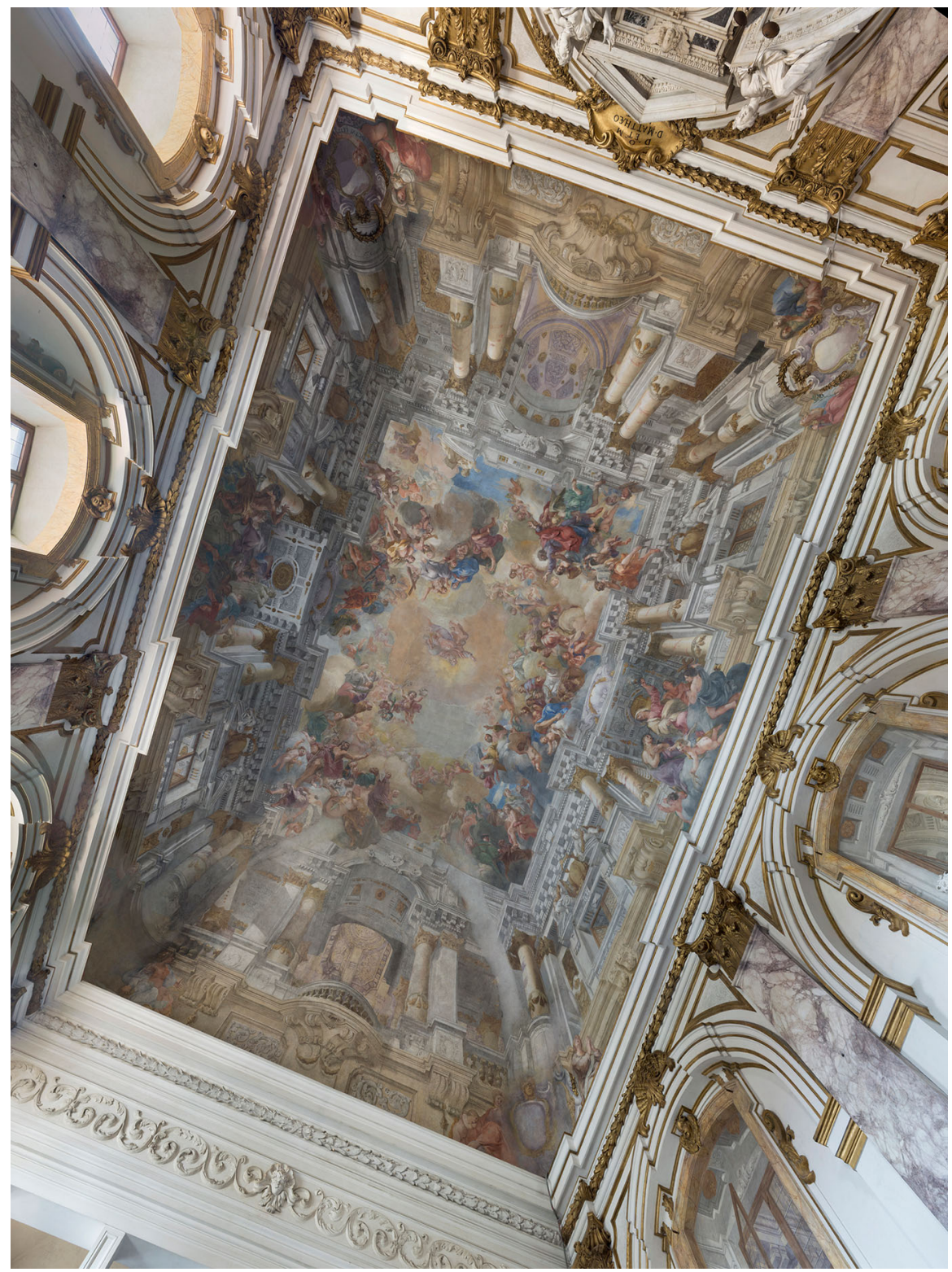

Fig. 1 Stitched panoramic image, created by PTGui. The nodal point is close to the privileged viewpoint. Focal length: $50 \mathrm{~mm}$ (fixed), Number of photos: 117, Dimensions: $6016 \times 4000$ pixels. Note: the depicted cornices are not always parallel to the real ones; the shape of the lateral balconies is not very conventional and their balustrades are not parallel to their base 


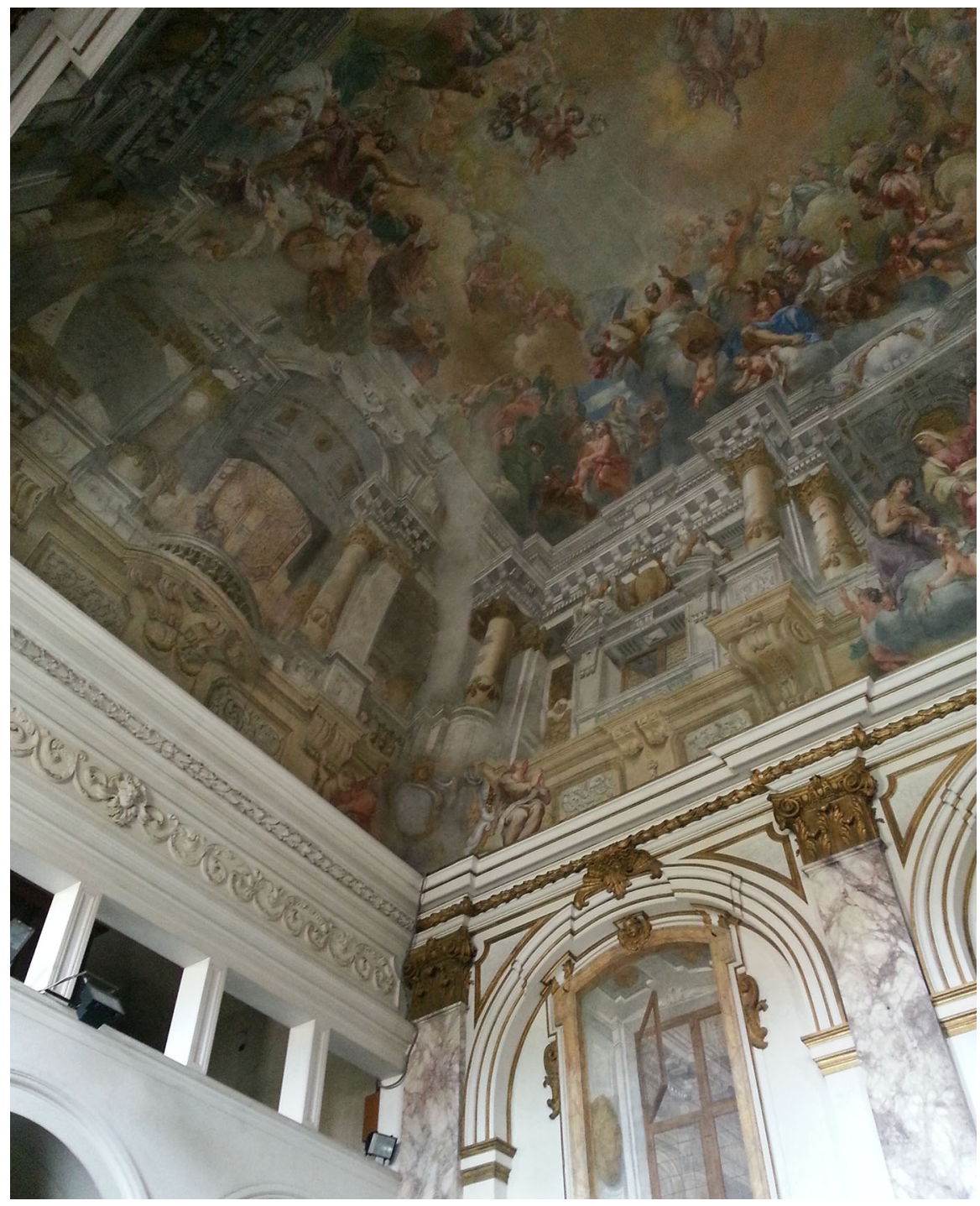

Fig. 2 The camera's nodal point is not close to the privileged viewpoint. Photo by author

\section{Geometry of the Vault}

The Church of San Matteo has a unique trapezial nave covered with a painted cloister vault. The fresco represents La Gloria di San Matteo. The ground floor plan is a scalene trapezium with medians that measure $21 \times 33$ Florentine braccia, ${ }^{6}$

\footnotetext{
${ }^{6}$ One Florentine braccio (pl. braccio) is $0.5836 \mathrm{~m}$.
} 

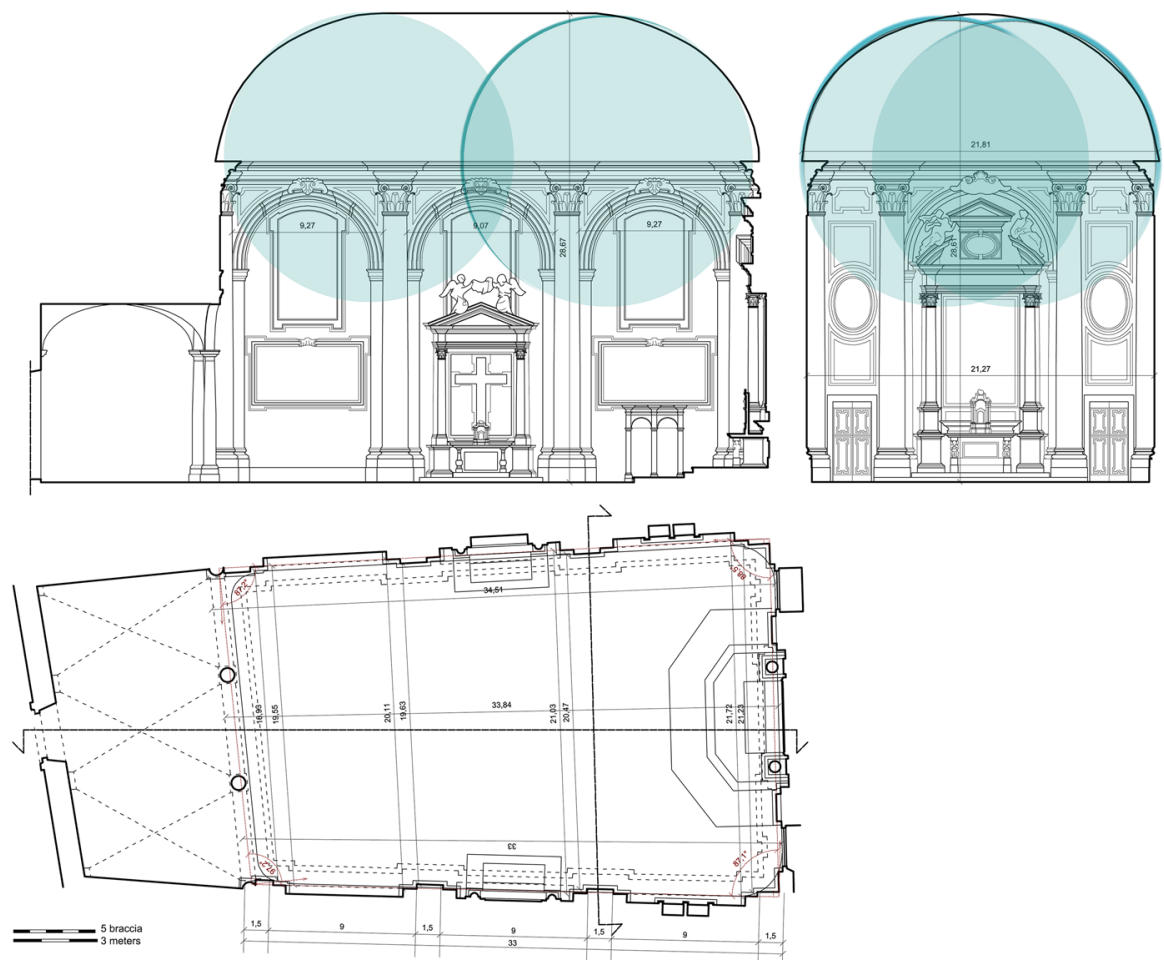

Fig. 3 Ground floor plan and sections. The circles shown in the figure correspond to the hypothesized regular cloister vault

delimited by three acute angles and one obtuse angle that is more than $7^{\circ}$ greater than a right angle.

The geometry of the vault is currently very irregular, probably due to the earthquakes and other structural damages sustained during the centuries. The sets of mesh $^{7}$ model sections are showing the tendency towards a regular cloister vault geometry where the sections are given by a curve made of two circular arches and a straight line between them. The three dimensional model done on this base differs slightly from the surveyed model (Figs. 3, 4).

\section{Data Processing}

The processing of the collected data was carried out in two parallel stages. The first stage was the image processing and realization of the rectilinear panoramic image. In this stage we used both photogrammetric and metric data (point cloud). These two data sets allowed us to reconstruct the position of the camera's viewpoint in

\footnotetext{
7 A polygon mesh is a collection of vertices, edges and faces that defines the shape of a polyhedral object in three dimensions. The network of triangles is built over the existing vertices of the point cloud.
} 


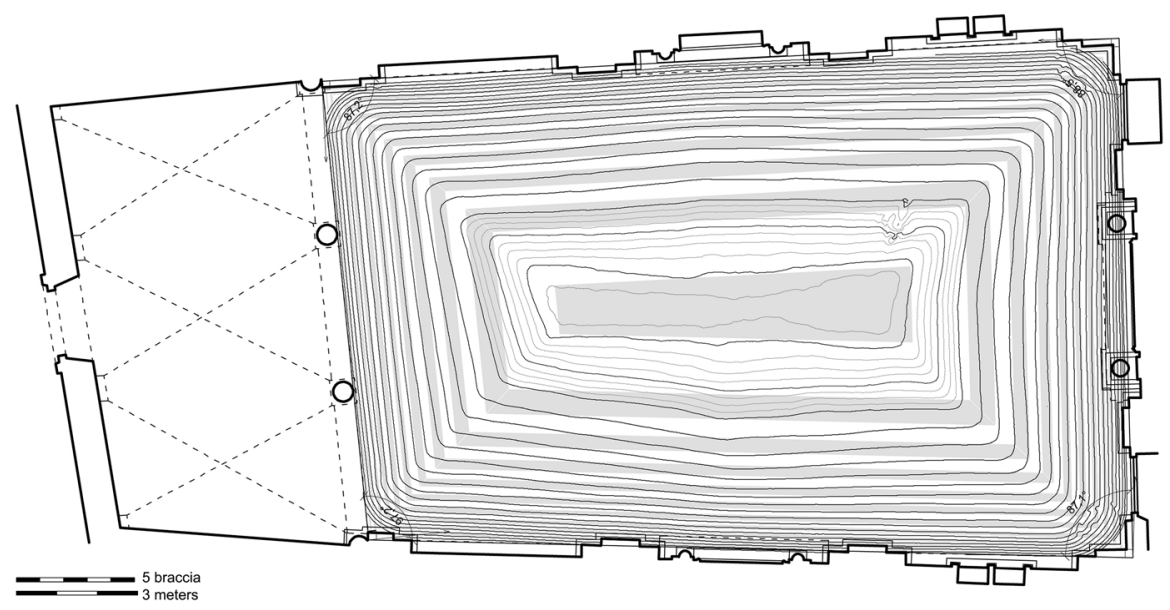

Fig. 4 Ground floor plan with the projection of the vault's contour lines (mesh model horizontal sections) overlapped by the contour lines of the regular cloister vault (gray stripes)

three dimensions. The panoramic image was oriented parallel to the horizontal plane. $^{8}$

The second stage of data processing was the three-dimensional reconstruction of the drawing onto the cloud point based mesh surface. Once we had that drawing were able to find the privileged viewpoint position and reconstruct the plain bozzetto.

The first three-dimensional reconstruction was done according to the cloud point snapshot. The vector drawing that was done on this basis (the orthographic projection of the cloud of points) was re-projected onto the vault surface (from the same infinity center) in order to obtain the three-dimensional reconstruction of the lines that compose the painting. Once we have the precise position of these lines on the vault surface we can find the privileged viewpoint; this is given by the intersection of the projective planes shown in a figure (Fig. 5). The vertical visual axis is given by intersection of the set of vertical projective planes, and the exact position of the point on that axis is given by the intersection of oblique projective planes. The oblique planes contain the horizontal lines that are transformed in ellipses onto the cylindrical surface. ${ }^{9}$ The reconstructed viewpoint position was at the height of around three Florentine braccia.

By re-projecting the spatial vector drawing from the vault onto the horizontal plane, according to the viewpoint, we obtained the bozzetto. That bozzetto,

\footnotetext{
${ }^{8}$ Camera calibration was based on horizontal plane. In this case it is very easy to get the rectilinear panoramic image oriented parallel to the same plane. The only thing to be done, in this case, is the alignment of the center of the panorama with the point where the last sequence of photograms intersects. If the orientation was done accurately, the vertical elements contained in the photo should have a vanishing point in the same spot. If this point is different we can still orient the panorama according to the vanishing point position. The center of the panorama, in this case, should be in this point.

9 This process has already been tested in one previous case study (Giannetti and Radojevic 2011). The vault, in that case, was a barrel and the ellipses were very evident. In this case we have a cloister vault and the process is only possible if the parts of the spatial curves are present (parts of ellipses in our case). Otherwise it is not possible to reconstruct the exact viewpoint height.
} 

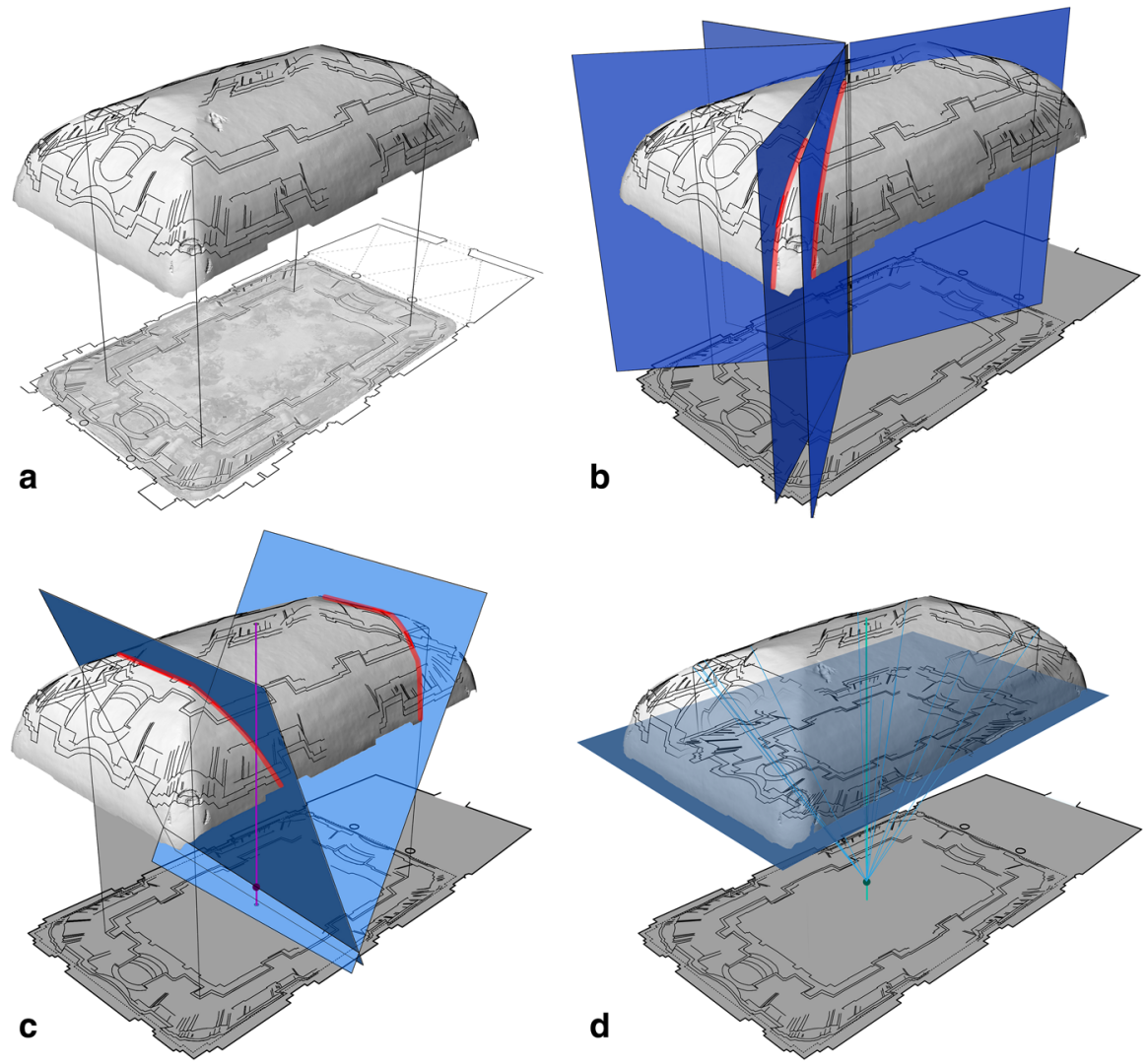

Fig. 5 Privileged viewpoint reconstruction procedure: a orthographic projection of the snapshot redesign onto the mesh surface. b View axis identification, based on the vertical projective planes. The red lines show the considered three-dimensional drawing curves. c Viewpoint's height identification, based on the inclined projective planes. The red line shows the spatial curve that the plane passes through. Almost all visible vertical and inclined planes were considered in the reconstruction process, and they produced very close results ( $5 \mathrm{~cm}$ range). $\mathbf{b}$ and $\mathbf{c}$ show only some of them. $\mathbf{d}$ Bozzetto reconstruction. Central projection of the three-dimensional drawing from the privileged viewpoint (color figure online)

afterwards, was overlapped with the panoramic image. The two graphics were almost the same because the camera's nodal point position was very close to the reconstructed privileged viewpoint (less than $5 \mathrm{~cm}$ lower, as discovered later). For that reason, we decided to use the panoramic image as if it was the bozzetto (Fig. 6).

\section{Bozzetto Realisation}

The first issue that we need to analyze is the possible operational way to make a preparation drawing for such an irregular plan (scalene trapezium). When we deal with a rectangular floor plane we need to make only a portion of a bozzetto and then multiply it by taking advantage of symmetrical characteristics of the structure, as 


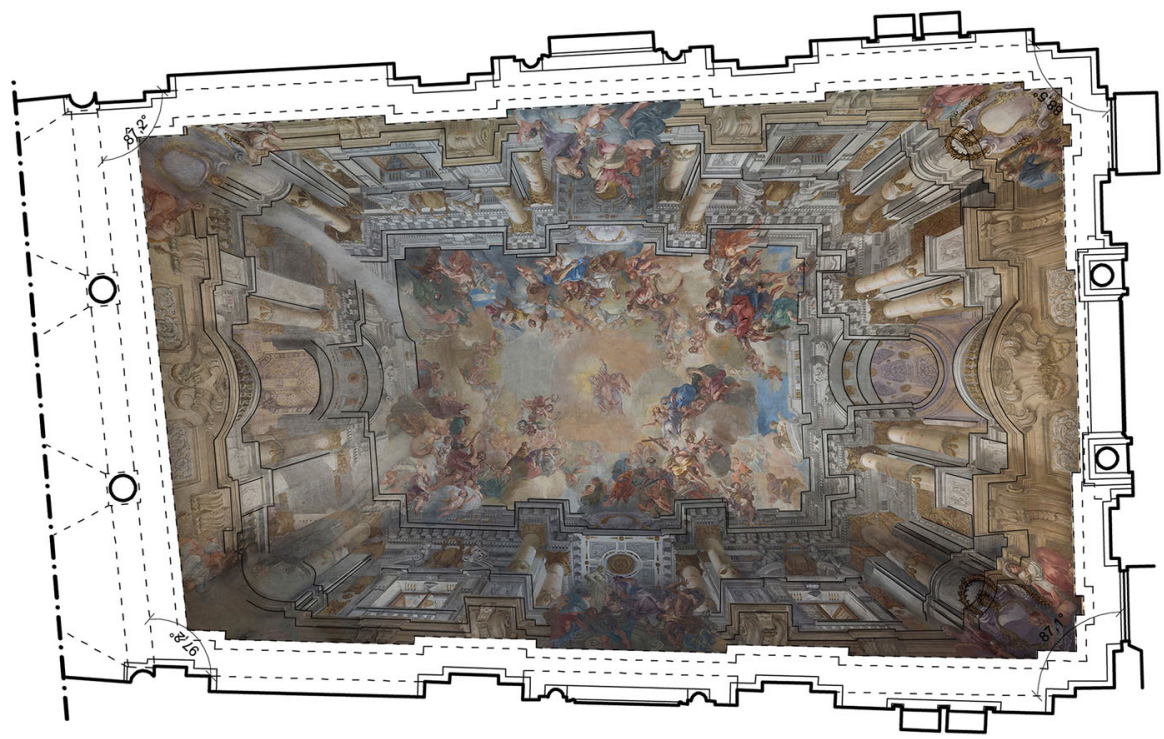

Fig. 6 The rectilinear panorama overlapped by reconstructed bozzetto. The bozzetto shown in this figure was obtained on the basis of laser scanner data, as described in Fig. 5

often happens in quadraturism praxis $^{10}$ (Vignola 1583). In order to do a similar thing on trapezoidal bases we need to rotate and adjust the portions of a rectangular drawing.

The preparation drawing for the quadratura of the Church of San Matteo is not available nowadays but if we attentively observe the metric qualities of depicted architectural orders we can draw some considerations concerning the original bozzetto (Fig. 7). The re-constructed height of the depicted architecture turns out to be equal to the distance from the viewpoint ${ }^{11}$ to the vault impost. This particular height is suggesting the method that could have been adopted for the bozzetto realization. This method consists in a particular use of a flat mirror and a scaled three-dimensional model of the composition that we want to draw. It was codified by the Venetian geographer Cristoforo Sorte near the end of the sixteenth century. Sorte claimed that we need to make a scaled model (a portion) of the architecture we want to draw and place in onto the flat mirror that has a designed grid on its surface (Fig. 8). The image in the mirror depends on the observer's viewpoint position. If the observer's eye is placed on the top of the model the depicted architecture's height will be the same as the model height (obviously scaled) when seen from the symmetric point (that is the privileged viewpoint) ${ }^{12}$ (Sorte 1580).

\footnotetext{
${ }^{10}$ In some case studies the original bozzetto is conserved, and is realized in quarters (Radojevic 2011).

11 The viewpoint's height is three Florentine braccia from the ground floor level $(1.75 \mathrm{~m})$.

12 ... L'altro modo fu con un specchio, sopra il quale si tira con uno telarolo una graticula alla misura di esso specchio, e si graticula con revo o seta nera, e si divide in quanti quadretti si vuole, e poi mettesi detta graticula sopra ad esso specchio benissimo affermata; e volendo fingere dette colonne, figure o altro in scurzo in esso vòlto, si fa prima la cosa che vi si vuole dipingere di rilevo, ciò̀ in modello, e si pone alta alla misura come nella distanzia ci pare di fingere ... (Sorte 1580).
} 




Fig. 7 (Left) Bozzetto realization based on the scaled model of the depicted space reflected in the flat mirror. The scaled grid is $3 / 4$ of braccio. (Right) model front view scaled to the actual size (second floor) in relation to the church section

Considering the two horizontal lines that represent the limits of the upper cornice and the upper limit of the pedestal (Fig. 7), that should lie on the same vertical plane in any classical order, we constructed the three dimensional model on the rectangular base (Fig. 8). For the side lengths of the rectangle we took the trapezoid's medians measures (21 and 33 braccia). The vault impost height is 19.5 braccia, while the observer's viewpoint height is 3 braccia. Therefore, the distance from the observer's viewpoint to the vault impost is 16.5 braccia and is equal to the height of the upper depicted cornice $(33 / 2=16.5$ braccia $)$ ! This particularity can give many benefits in the executive phase.

The hypothesized grid that we need in all the phases of the process (from the scaled design on the mirror to the executive phase on the vaulted surface) is made from the $3 / 4$ braccia module. This module is very easy to use because it transforms all the fractional numbers into integers, facilitating the calculations that way! The quarter of the bozzetto, that is $10.5 \times 16.5$ braccia for instance, becomes $22 \times 14$ modules, and the height of the depicted architecture becomes 22 modules. The same line of the tridimensional grid that represents the upper cornice lies on the grid also in the perspective drawing. It is exactly in the middle of the bozzetto grid! Also the line that represents the pedestal lies on both the grids and the projective ray that 

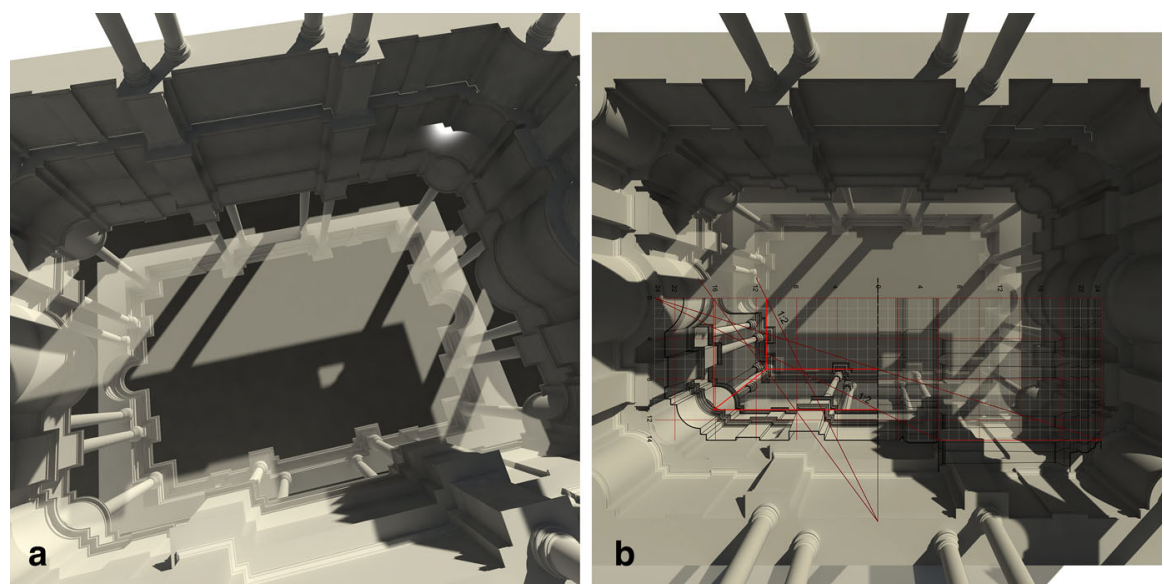

Fig. 8 Mirror based bozzetto realization method described by C. Sorte. Perspective view from the privileged viewpoint: a inclined projection plane, $\mathbf{b}$ horizontal projection plane. The image is overlapped by two-dimensional drawing obtained from the same model

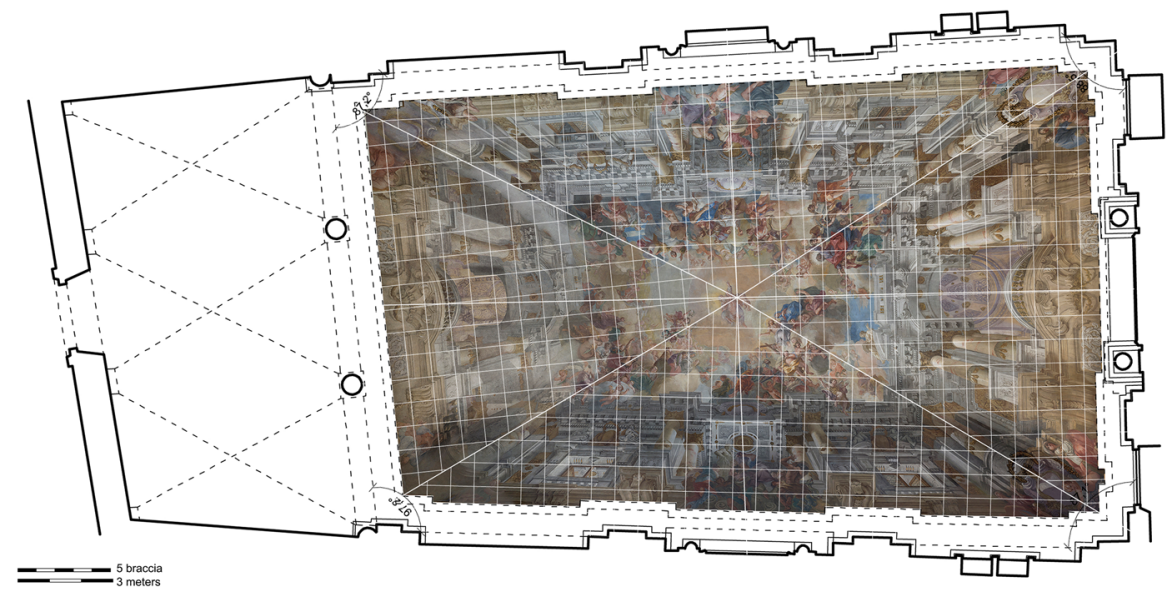

Fig. 9 Ground floor plan with flat bozzetto overlapped by hypothetical grid

contains it has a slope of 1:2 (Fig. 7). So we can clearly see the benefits that some particular integers can give us in the perspective drawing.

Once we have drawn our rectangular cartoons, we need to rotate, cut and adjust the drawing for the actual trapezial base. One of the clues that is visible in the painting, and could be the product of the described process, is the unfinished obtuse angle (Fig. 2). This part would be very difficult to accomplish in the described manner, because of the missing parts of the drawing and the directions that are difficult to combine together (Figs. 9, 10). Actually, it's only when we tried to adjust the rectangular pieces to the trapezoid base that we realized how difficult that task was. The painter could have used the mirrored rectangular image for the 




Fig. 10 Bozzetto overlapped by hypothetical 3D model's projection. The model was done on a rectangular basis

drawing of the details, but the trapezial perspective grid settings should have been made from scratch. In this part of the work he could take advantage of the precalculated main line's positions.

However, the described bozzetto construction procedure still does not give us any explanation of either the horizontal painted elements that are not always parallel to the vault's directions nor the strange forms of the lateral painted balconies and their balusters. In order to try to find some elements that could lead us to these answers we will try to examine the bozzetto transportation method onto the vault surface.

\section{From the Flat Drawing Towards the Vault Surface}

The transposition of the flat drawing onto the vaulted surface, as we have seen, can be done in two different manners:

- The first one is the direct projection, as described by Andrea Pozzo.

- The second possible method that we could use (partially described by Vignola) is the construction of the scaled model of the vault surface, a sort of central projection of the grid onto that model, and the enlargement of unrolled spindles (with the grid design) that compose the vault model. Once we have big unrolled cartoons we only need to adjust our flat preparation drawing according to the deformed grid. This operation does not produce any difference if two models are identical but, as we mentioned, the vaults are never geometrically ideal surfaces. Therefore, the scaled model will always be a kind of a simplification of the surface (especially in the past when the digital surveying instruments were not available). The other operative difficulty, in this method, is the grid design on the big unrolled cartoons. The grid lines, that are all straight in central projection, become very complex curves onto the unrolled spindles. 


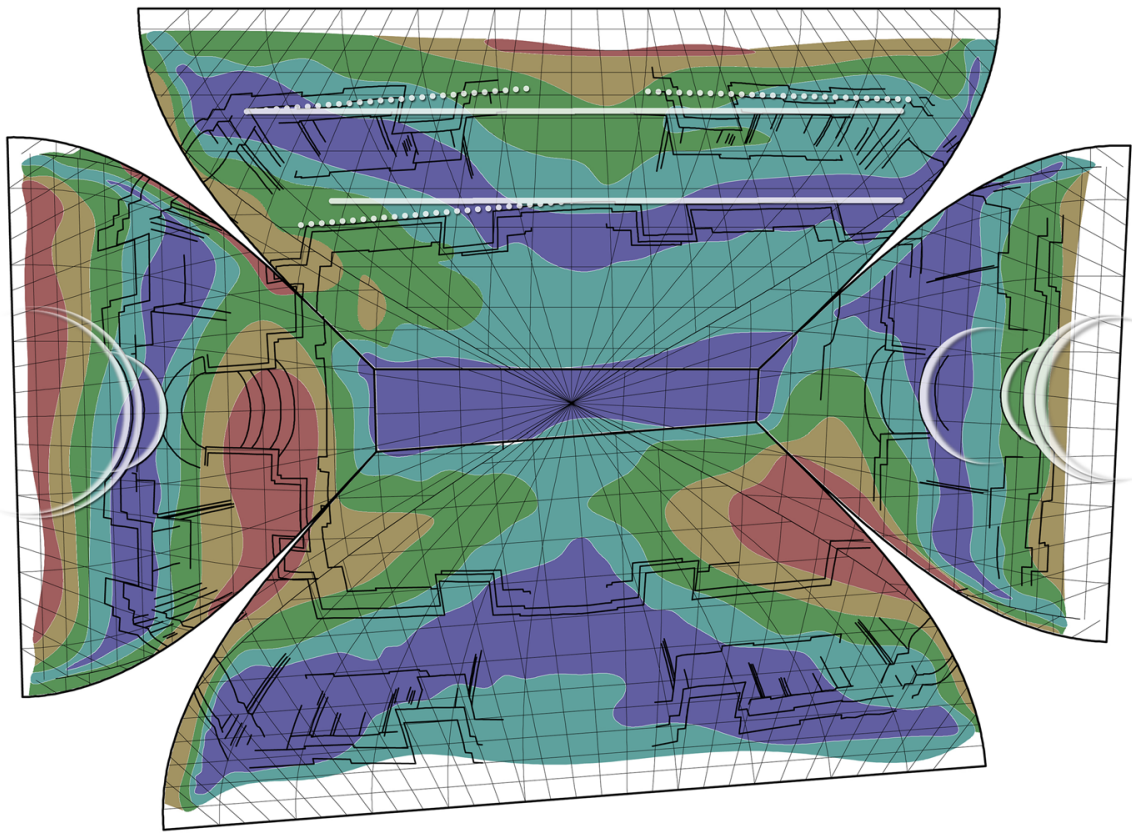

Fig. 11 Developed drawing overlapped by the discrepancy (between the regular cloister vault and the mesh model) color map (blue less than $3 \mathrm{~cm}$, red more than $12 \mathrm{~cm}$ ). To notice: the lines highlighted in white diverge from the grid in relation with the discrepancy map. The oddly shaped balconies become the concentric circular arches (color figure online)

In the case of the quadratura in the Church of San Matteo, some "incongruities" in the design are visible both in the orthogonal and the central projection. This fact suggests to us that the transposition of the flat drawing onto the vault surface was not done by the direct grid projection onto the real surface. Even if the deformations of the horizontal lines (that are not parallel to the vault's shape) could have happened after the design execution, the strange balcony design leaves doubts. They do not seem to be designed using any coherent geometrical method.

In order to verify the second hypothesis, we unrolled and analyzed the existing three-dimensional drawing. To make this operation possible, the mesh model has been simplified by the closest developable surface, composed of four regular cylinders. For the correctness of the interpretation of the results, the discrepancy between the two models has also been calculated and represented with different colors (Fig. 11). By overlapping the discrepancy color map with the unrolled vault spindles we are able to make some considerations:

- The horizontal lines, that should be parallel to the vault edges, are more divergent where the differences between the two models are greater. They are not following the grid in these zones.

- It can be observed that the horizontal lines are rotated outward in lower parts, and inward in the upper parts. This confirms the use of the cartoons in the 
execution process; because the rotation of the lines is actually produced by the different surface areas between the real vault and the scaled model (that the cartoons were based on). Where the simplified model has a smaller surface the lines rotate inward and vice versa.

- The most surprising fact is the shape of the balconies and the balusters above them in the unrolled projection. The strange lines, that we mentioned before, suddenly became concentric circles: they were designed directly onto the big unrolled cartoons!

\section{Conclusions-Case Study One}

The fact that there is a certain correspondence in the discrepancy between the two models (the real and the idealized one) and the drawing "irregularities" shows that the transposition from the flat perspective drawing onto the curved surface is not direct. Instead of the direct central projection of the grid onto the real vault we can rather think of some kind of a mechanic transposition method that allows one to find the actual shape of the unrolled grid directly onto the developed cartoons that represent the vault's surface (not the real one but the simplified scaled model). This "unrolled" projection can be found by applying different methods developed within geography and cartography. One of those would be the projection of the flat grid onto the scaled vault model, subsequently developed and enlarged. Another one would be the direct drawing of the grid onto the real scale developed cartoons, by the aid of the grid points whose position one could calculate. In both cases the reference model is a regular cloister vault that does not completely corresponds to the real one, and for that reason the process itself produces some discrepancies (even when the real vault is seen from the exact viewpoint). The transposition of the enlarged cartoons, in both cases, onto the vault surface is by pouncing charcoal dust through the perforations in the points that we need.

\section{Case Study Two: Church of Santa Caterina in Livorno}

The oval apse's wall in the San Giuseppe Chapel in the Church of Santa Caterina in Livorno was depicted by Jacopo and Giuseppe Terreni in the second half of the eighteenth century, and it represents the "Sposalizio della Vergine". The depicted architecture, at first sight, does not seem architectonically very "probable". The illusory space is bounded by two lateral straight walls and coffered ceiling, but the back wall is ambiguous. While we are walking towards the apse it appears as rectangular in the beginning (when we are far away) and suddenly becomes circular when we are near the apse's center (Fig. 12). Another strange issue is the big arched opening in the same wall: the shape of the arch appears as very strange from any viewpoint. It does not appear as either circular or oval, and it seems to relapse downward! One more issue that seems unusual is the coffered ceiling. The coffer's border lines do not seem to be parallel to each other, especially in the parts that are close to the edge of the ceiling. 

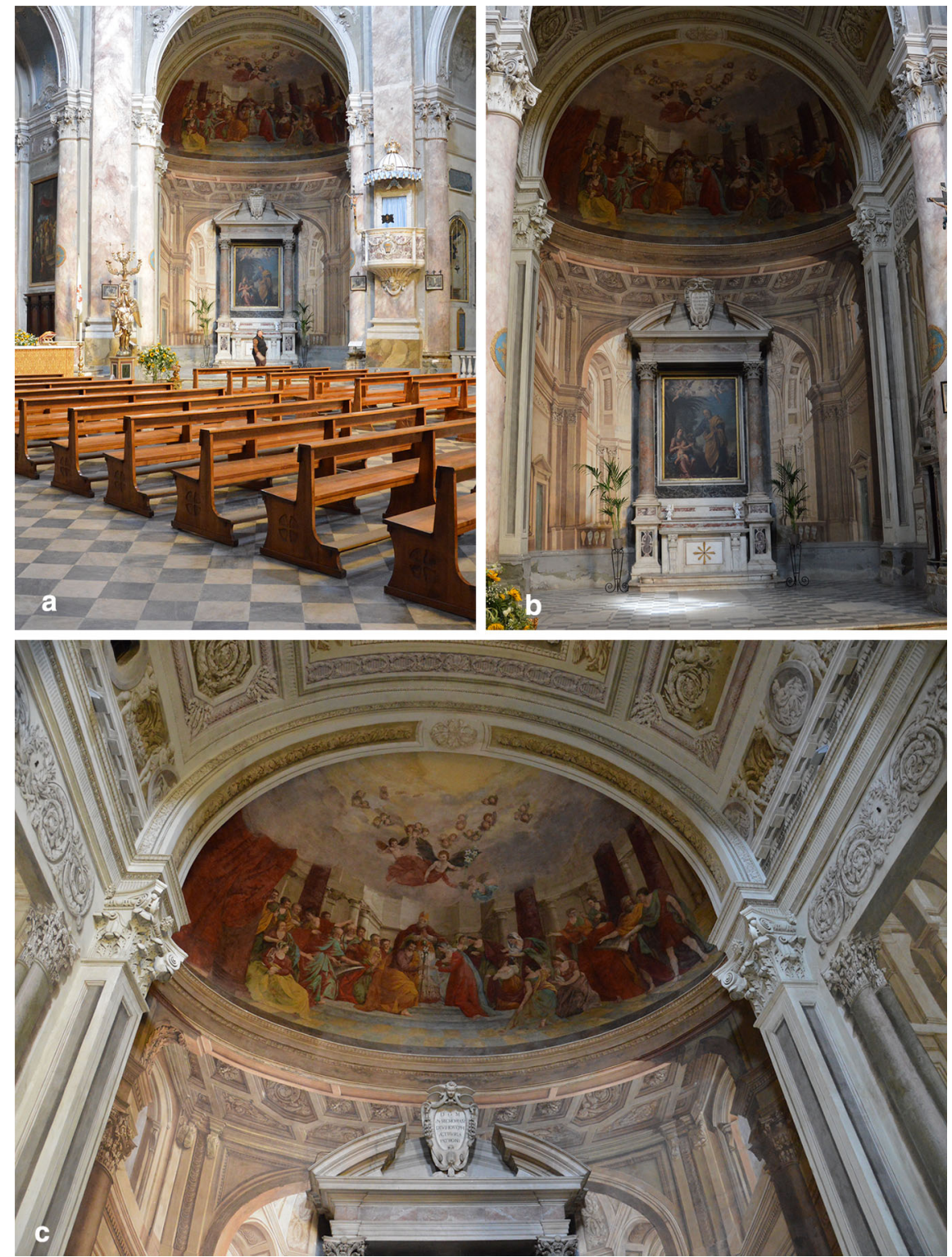

Fig. 12 Photos shown in these images were taken in the movement towards the privileged viewpoint (ac). We can notice the different depicted space perception from position a-c. The depth of the depicted space also appears to decrease 


\section{Data Processing}

In order to analyze both metric and geometric properties ${ }^{13}$ of the painting the first necessary step was the three-dimensional restitution of the recorded data, with special attention to architectural elements' drawings. Also in this case, the restitution was based on both the panoramic hi-resolution image and the metric data provided by laser scanner. After the panoramic image stitching into a single rectilinear $^{14}$ frame, the spatial restitution of the camera's nodal point was done. This process was done by applying the inverse perspective methods on the basis of the rectilinear panorama projected onto the inclined picture plane (Figs. 13, 14). From this frame, it was possible to deduce both the observer's distance and the visual ray's inclination with respect to the picture plane. The necessary metric data for this operation (at least one distance) were provided from a snapshot ${ }^{15}$ of a ground floor plane (Fig. 14). At this point, we have a hi-resolution image (rectilinear), the camera's nodal point position (center of projection) and we can easily obtain the three-dimensional depicted wall surface from a point cloud. Once we have vectorized the hi-resolution image, we only need to project the lines from the nodal point onto the mesh surface (Fig. 15).

Although the whole restitution process could have been done as described above, for practical reasons, ${ }^{16}$ we did the re-design based on the new panorama, projected on a vertical picture plane (Fig. 16). The picture plane is very easy to orient in this case: once we know the vanishing point of the lines perpendicular to the picture plane that we want to orient our panorama to, ${ }^{17}$ we only need to juxtapose the center of the new panorama with the corresponding pixel (Fig. 14). The panorama image oriented to the vertical plane was vectorized, and the lines were re-projected, from the nodal point, onto the mesh surface. The same operation could have been done on the basis of the orthogonal point cloud based snapshot, but it would produce minor accuracy because of both image quality and excessive foreshortening of some zones (the edges of the cylinder). The cloud point based snapshot was used to verify the whole process $^{18}$ in this case (Fig. 17).

\footnotetext{
13 All the analysis is based on the integrated survey. The integrated survey data collection (terrestrial laser scanner data and panoramic images) of San Giuseppe Chapel was done in 2014 within the research project "Architectural Perspectives". The photographs were taken from the single nodal point, by the aid of a panoramic tripod head, in order to be stitched in hi-resolution panoramas.

14 Rectilinear panorama is obtained by projecting the panosphere onto the two-dimensional plane. Lines that are straight in reality are shown as straight regardless of their directions on the image. Wide viewsaround $120^{\circ}$ or so-start to exhibit severe distortion near the image borders.

15 Snapshot is the raster image taken from a point cloud, overlapped by the metric grid in this case.

16 This image is much easier to vectorize inasmuch as a lot of lines are parallel to each other in this projection.

17 We can deduce the vanishing point of these rays once we have created any rectilinear panorama, but only if these lines are contained in our image (in our case we have a lot of edges that are perpendicular to the picture plane).

18 The vectorized drawing in orthogonal projection was obtained from a three dimensional drawing, that was created from the central projection (panorama image).
} 


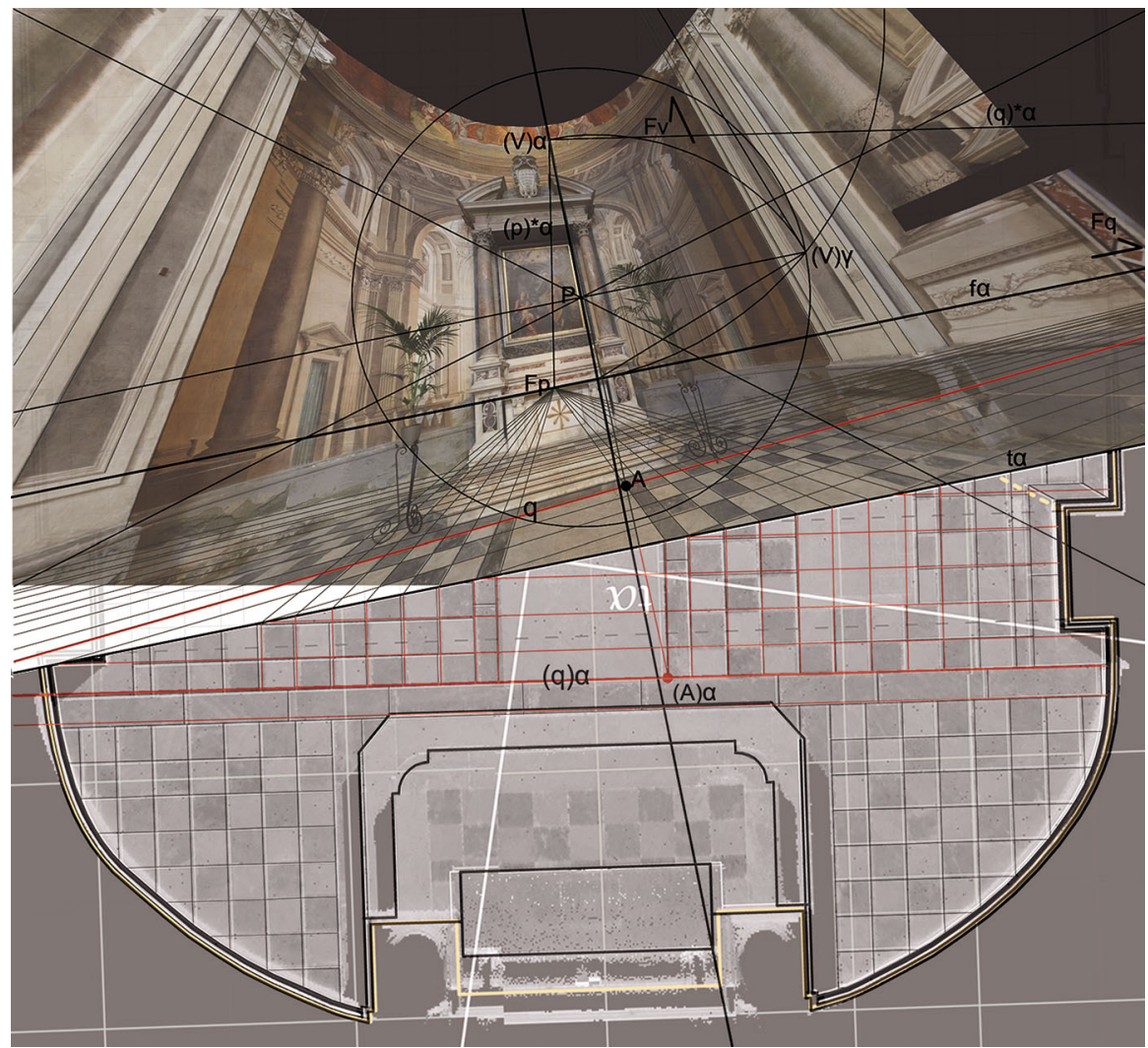

Fig. 13 Camera's nodal point restitution process from the rectilinear panoramic image (onto inclined plane) and metric data (cloud point snapshot): three sets of lines perpendicular to each determine three vanishing points. According to the perpendicularity conditions we can reconstruct the spatial position of the center of projection (pyramid vertex)

\section{Data Analysis}

If we observe the orthographic projection of the quadratura, we can immediately notice that the horizontal lines (parallel to the picture plane) remain parallel to each other even in this projection (Fig. 17). This occurrence, for the perspective drawing on the curved surface, could only be possible in two cases:

1. The depicted space corresponds to a rectangular spatial configuration, and the curved surface was not mapped according to exact geometrical and projective principles. The quadratura was designed as if it was meant for the flat surface and then simplistically curved.

2. The depicted space corresponds to a circular spatial configuration (where the apse's wall and the depicted one are concentric circles) and it was projected onto the curved surface from its center. In this case, all the points are 


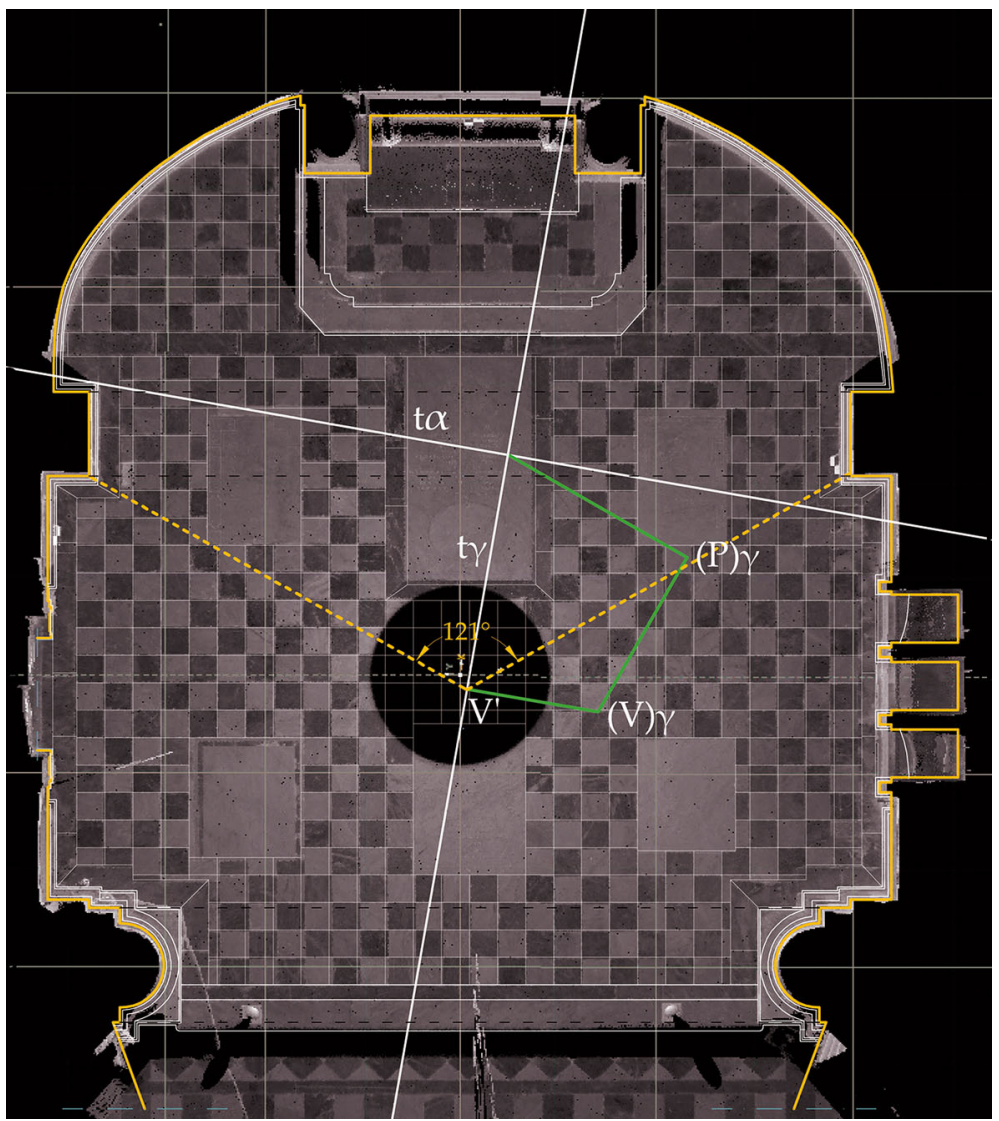

Fig. 14 Floor plan snapshot: the rotated nodal point $(V) \gamma$ onto the floor plane. In order to find this point in space we only need to rotate it around the $\mathrm{t} \gamma$ axis for $90^{\circ}$

equidistant from a cylinder (the surface of projection) and they are actually seen as horizontal in orthographic projection.

Furthermore if the applied method was geometrically coherent, as in the second case, how can we explain the irregularities of the arch's and coffers' design?

The analysis that we were able to do on the basis of the three-dimensional model produced some results that can suggest on which principles the design process was grounded. The developed surface drawing shows some very expectable and particular characteristics. The strange arch, that was supposed to be very irregular in this projection, suddenly becomes circular. That leads us to think that the design process actually started from this drawing, as in the San Matteo case.

Another issue is the unique vanishing point for the lines that are perpendicular to the picture plane. This point, that is not unique either in central or in orthographic 


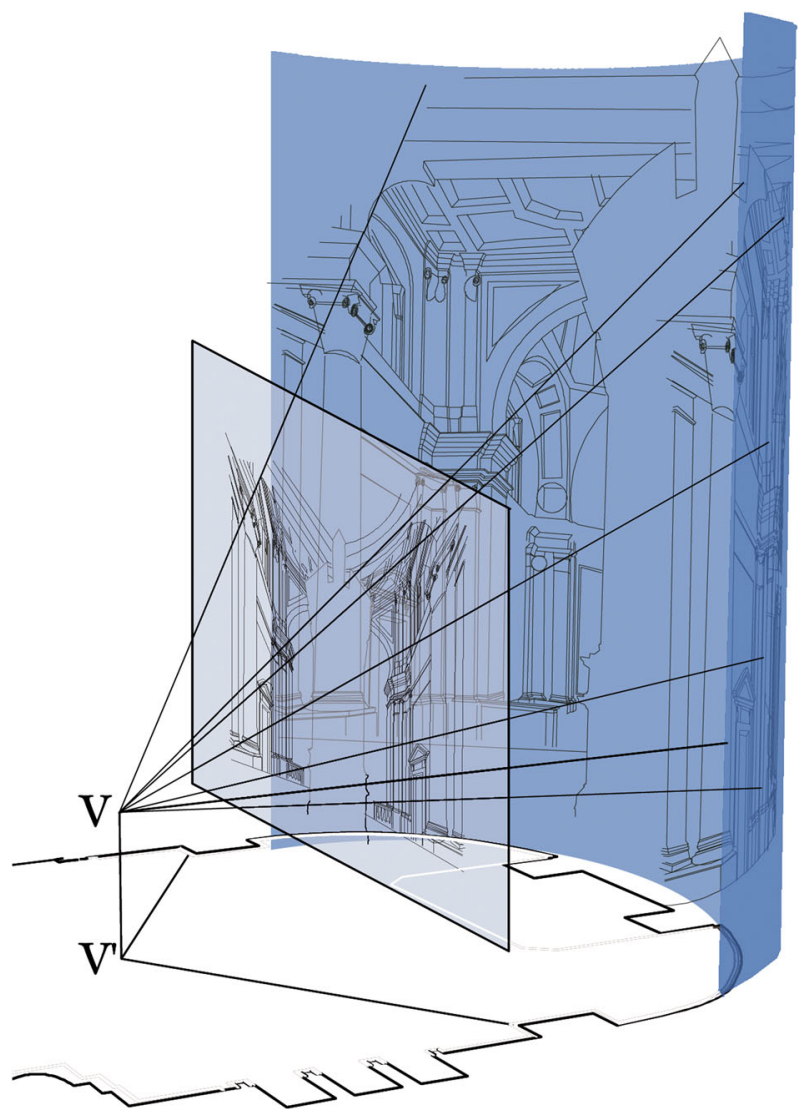

Fig. 15 Central projection of the re-designed panorama onto the mesh surface in order to obtain the three-dimensional drawing

projection (Figs. 18, 19), does not become such either in developed projection (Fig. 20). That leads us to exclude, almost surely, the case 1 (the drawing was made as if it was on the flat surface). For further analyses of these lines, we constructed the regular wire grid that was projected onto the surface (from the center of the cylinder), developed and overlapped with the developed design (Fig. 20). This grid, which we see as flat both in orthographic and central projection, once developed becomes curved. If we try to simplify this grid, by making the lines straight (we consider first two points of it as shown in the figure), we come to another surprise. The straightened lines become almost coincident with the ones from the drawing (that seemed to make no sense) with great precision.

\section{Conclusions-Case Study Two}

So, we can conclude that the artist considered all projective principles of this spatial transformation (that pertains to cartography) and understood them very well, to the 


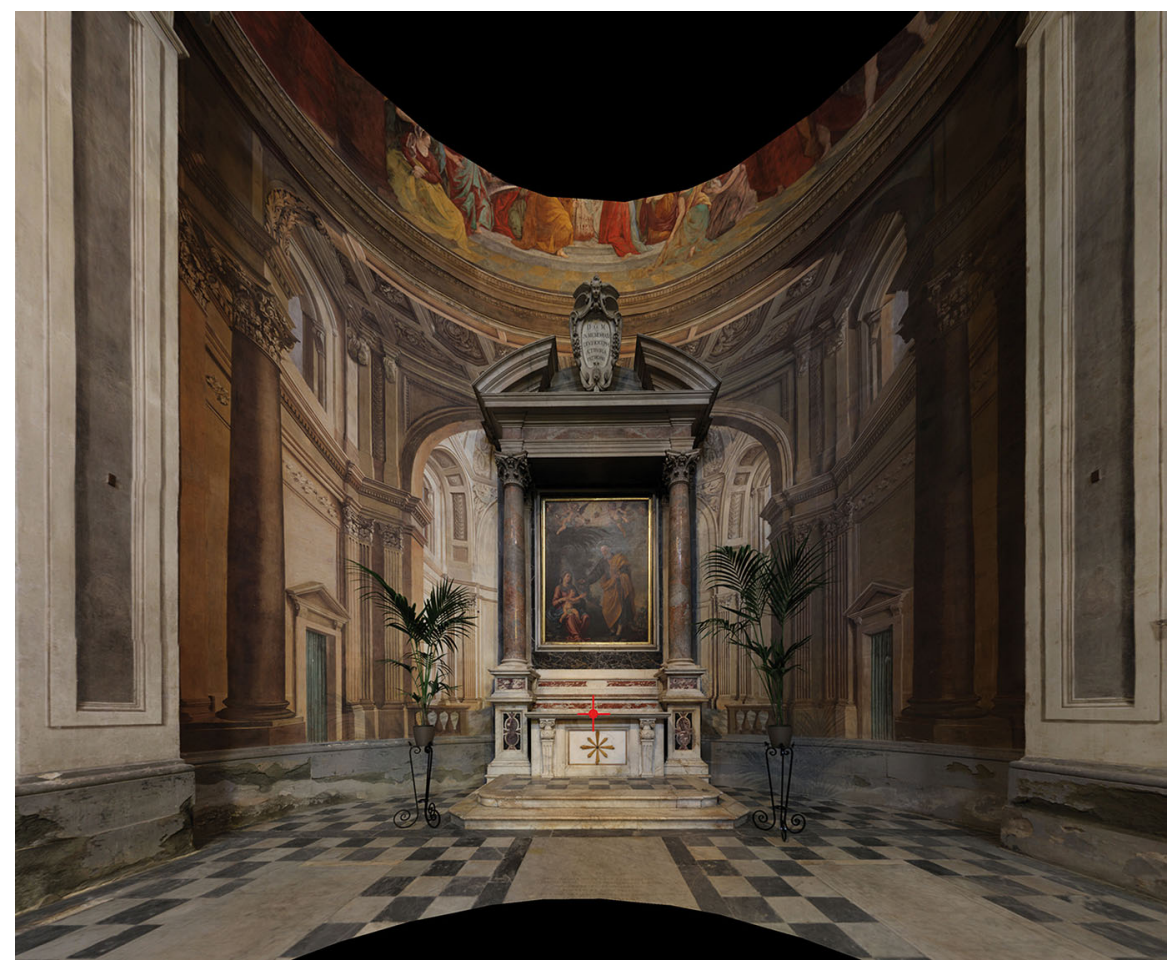

Fig. 16 Rectilinear panorama projected onto the vertical picture plane. The red spot shows the picture center that corresponds with the Fp point on Fig. 13. The horizontal visual angle is $121^{\circ}$ due to aligning the pilaster's edge with the picture's limit. The same angle is shown on the floor plane in Fig. 14

point at which he felt free to modify the rule. He didnot use any expedient (like shadows on the scaled model) but he constructed (maybe by calculation) the exact position of some points directly on the developed surface. ${ }^{19}$ At this point, we can

\footnotetext{
19 The Terreni brothers, who were mainly involved in landscape representation, were probably aware of the functionality of Baldassare Lanci's surveying device for tracing a sight onto a cylindrical surface (to be developed afterwards). The kind of representation produced by this device (the one criticized by Danti) is very useful to represent very wide landscapes, because the central projection onto the plane, in this case, would produce very strong distortions. Baldassare Lanci's surveying instrument may be operated as a theodolite, a geometric square, or a perspective machine. For the first two applications, the surveyor employs its compass, scale of degrees, and shadow square. The sliding bar supporting the two folding arms is shifted to the right in order to position the right arm in the center of the instrument, where it functions as an alidade for measuring the horizontal angles. The perspective operation of the instrument was principally conceived for military purposes, whereby the surveyor's perspective drawing of the likes of a fortress was used to render the building's plan, but it can be also used for other purposes.

If the image designed by this device is viewed in its curved form, corresponding to the original disposition of the drawing surface, it will give the panoramic effect which is not essentially in conflict with the optics of the standard method; it is only when it's unrolled and seen flat that it will produce very different results. As Danti explained, the intervals between equally spaced objects across a plane perpendicular to the axis of the viewer's sight will appear to diminish towards the outer ends, in contrast to the normal intersection method, in which such intervals remain constant. The effect, for example, of the wide wall divided by uprights depicted according to Lanci's method would be to show the top and the
} 


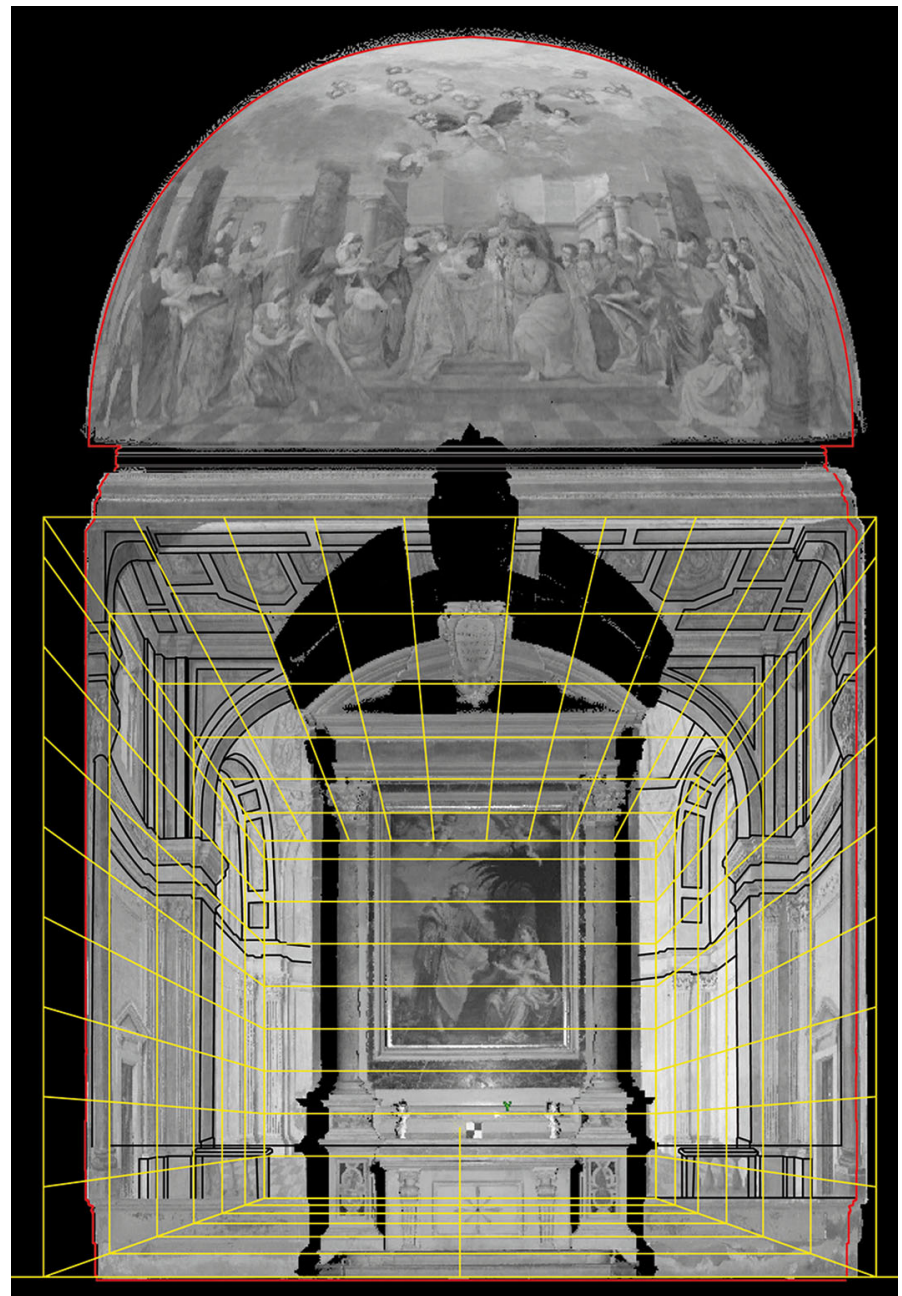

Fig. 17 Cloud point's snapshot overlapped by the three-dimensional design's projection

also claim that the executive phase was carried on with the aid of developed cartoons. We can say this because it is actually in this projection (developed) where he simplified the design (by replacing some complex curves with lines and circumferences) just as in the first case study.

What still remains unusual is the depth of the depicted space. If we try to reconstruct it from the cylinder center the architecture represented in the painting

(Footnote 19 continued)

bottom of the wall curving progressively together at the extremities, with decreased intervals between uprights. Danti makes it quite clear that he by no means approves these results, since it is not the accurate representation of the visual pyramid, unless it is arranged specifically as a curved section (Vignola 1583, p. 61). 


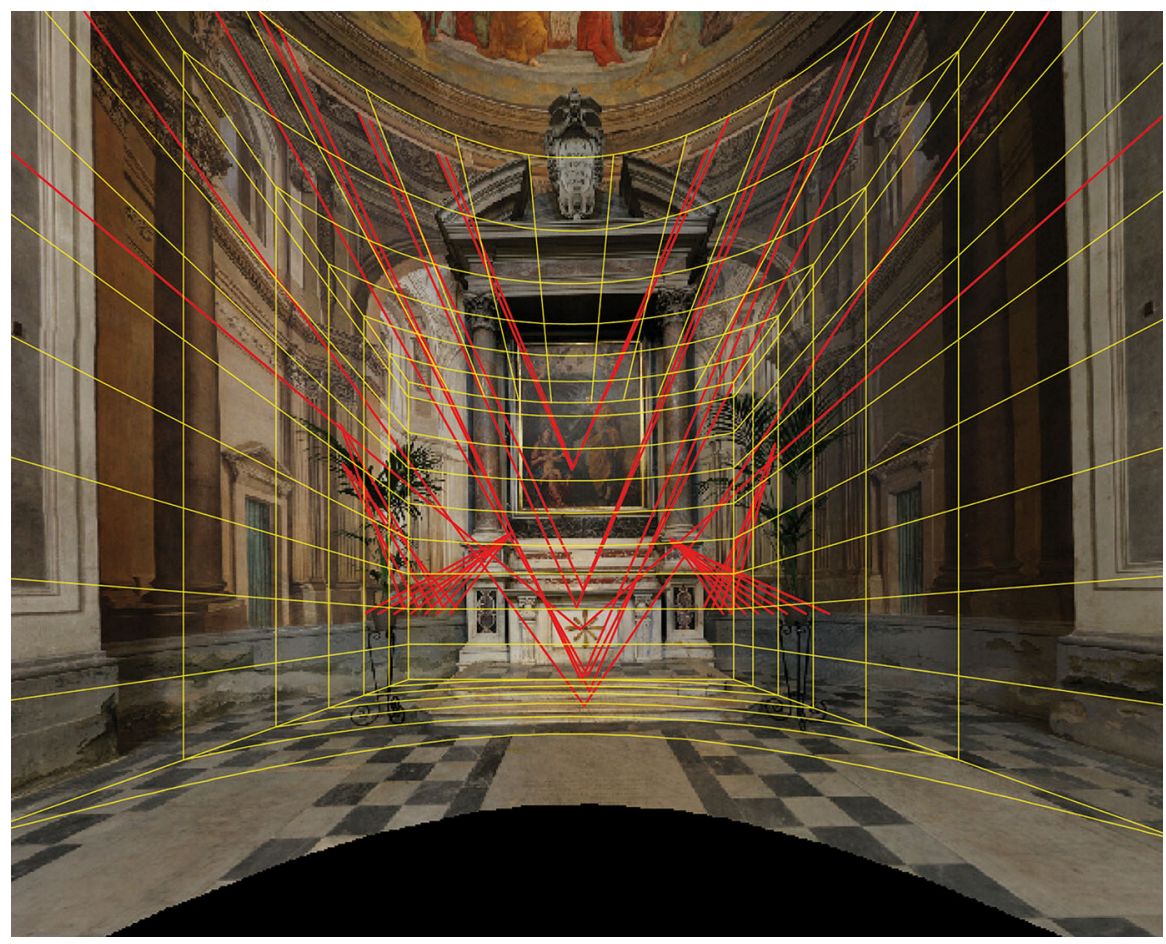

Fig. 18 The yellow grid, overlapped by the panoramic image, represents a central projection of a regular grid onto the same surface. The red lines are extensions of some of the design's edges. They do not converge towards a unique vanishing point (color figure online)

would be very shallow (a bit more than one Florentine braccio), while, according to architectural elements represented in the drawing, it should correspond to a space of five Florentine braccia (more or less) deep. In order to attempt to explain this occurrence, we made a simulation of five braccia deep space that was firstly projected onto the wall surface and then seen from different viewpoints (Radojevic 2015). It became clear that thus designed space appears much deeper than it should from all other viewpoints. So, the fake deepness can be understood as a conscious artist's choice, rather than "drawing error". The compromise made in this choice is affecting only one viewpoint (the privileged one) and is making the drawing seem more convincing from all others. It would be hard to believe that the same person that considered all the drawing deformations onto a developed surface could make such an error without being aware of it. The choice of the curved space, rather than rectangular, could have been made because the rectangular one would also seem realistic only from a single viewpoint. 


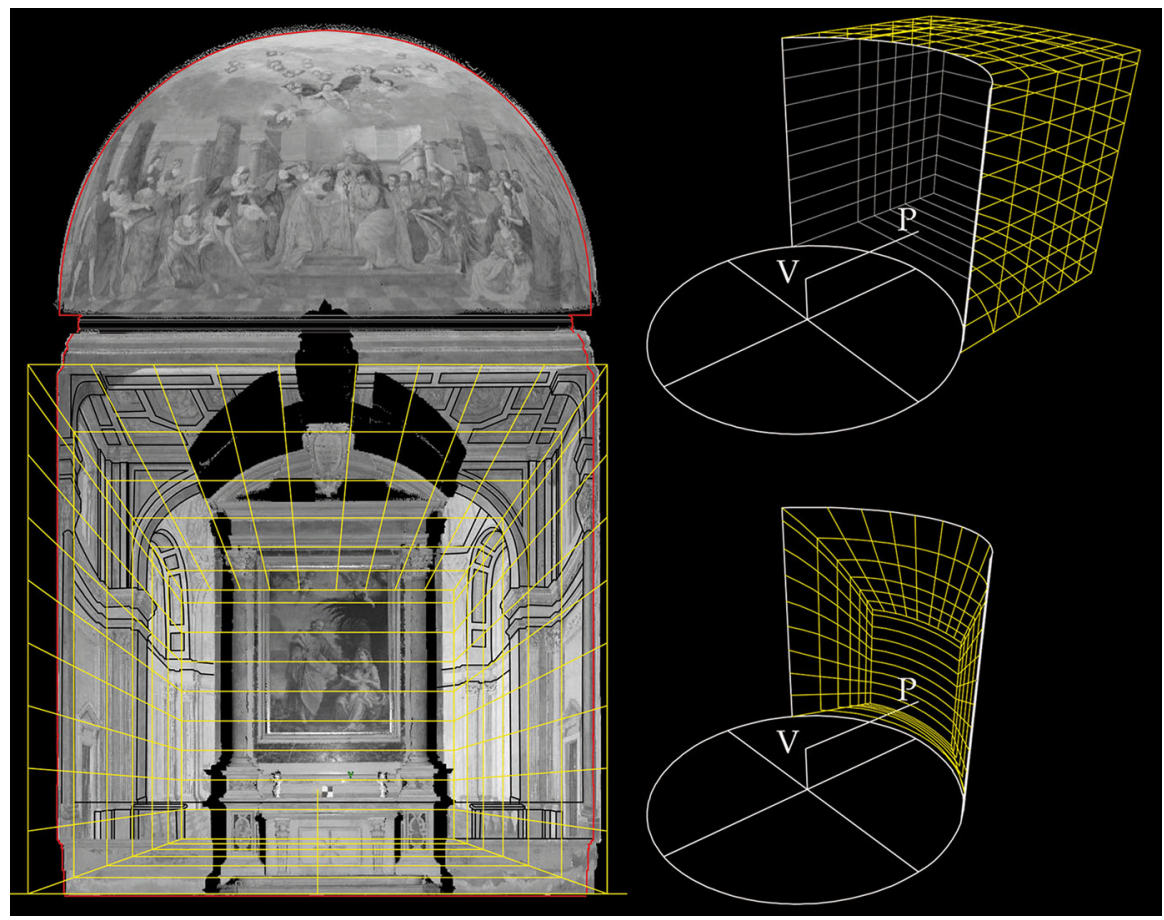

Fig. 19 The same grid as in Fig. 18, overlapped by orthographic projection. On the right side: the spatial configuration of the grid

\section{Conclusion}

With those dynamic inputs the artist is opening a discussion about the field of view issues that, as far as we know, were never discussed in literature. For example, in his famous treatise Le due regole della prospettiva pratica, Vignola claimed that the field of view needs to be fixed at $60^{\circ}$ (Vignola 1583) and he suggested the multiple view points for long and low spaces, the stance theorized later by Palomino de Castro y Velasco in his treatise El museo pictorico, y escala óptica (1795). Some studies of the quadraturism practice, conversely, show that these stances were not considered by most of their contemporaries (Migliari 2005; Bartoli and Fossi 2006; Radojevic 2011).

The depicted oval apse wall in San Giuseppe Chapel ends with the cornice that supports a semi-oval cupola. The perspective drawing of the rectangular illusionistic space behind the existing wall would be contradictory to the real spatial configuration. The fact that it's a drawing would be very perceivable, especially near the cornice, where the real and illusory fits together. From other points of view those lines would be bent in the opposite directions (Radojevic 2015).

For small size spaces, where the observer's viewpoint should be close to the depicted area, the drawing deformation itself is really accentuated. These distortions, which are not perceptible when we are standing in the privileged 


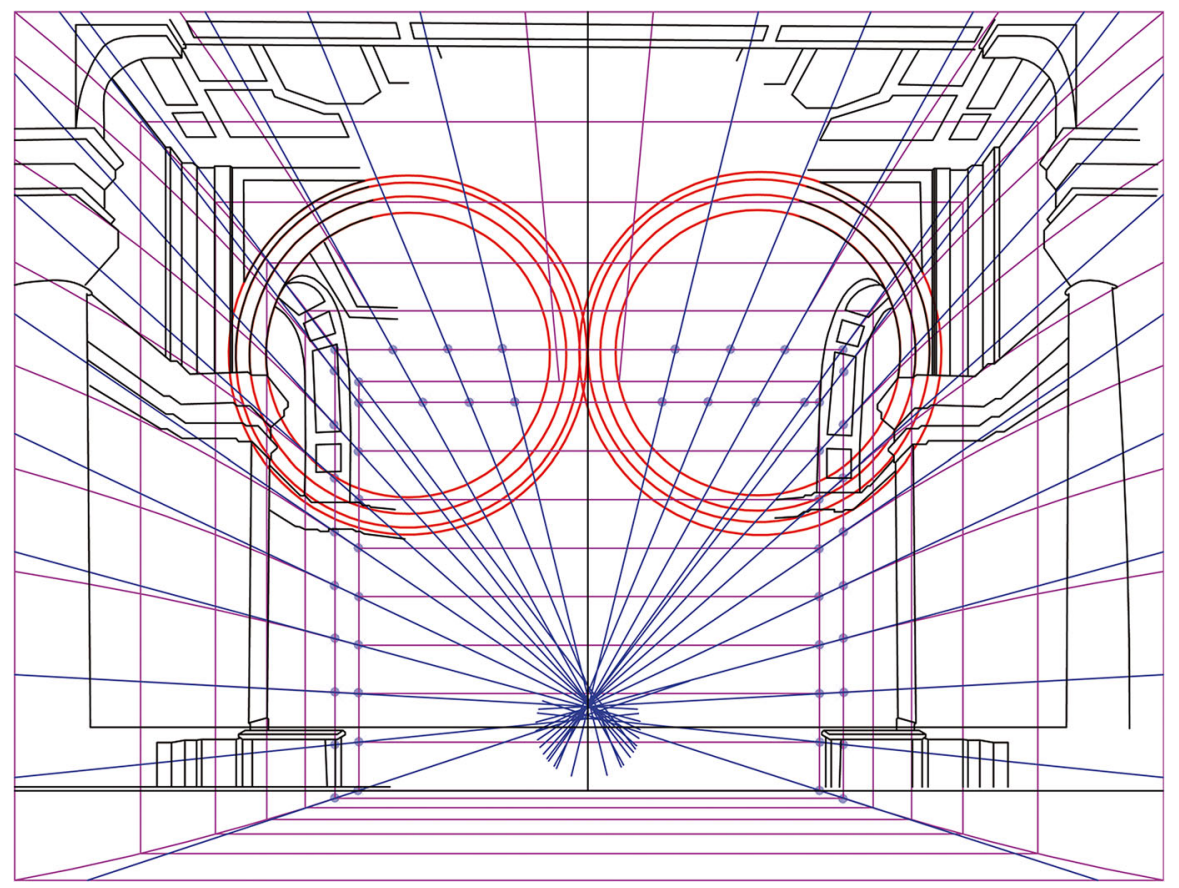

Fig. 20 Developed design. Violet the same grid as shown in Figs. 18 and 19. We can notice that the lines that should be perpendicular to the picture plane do not follow this grid. What is curious is the great correspondence between the blue grid and the design. The blue grid is a kind of simplification from the violet one, obtained by connecting the highlighted dots (in blue). Another thing to notice is the big arch that becomes perfectly circular in this projection (as in the San Matteo case) (color figure online)

viewpoint, are very noticeable when we are out of it. The difference between the ceiling and parietal paintings is the orientation of the view axis, which is vertical in the first case, and horizontal in the second. This issue affects the observer's liberty of movement. In the ceiling case he cannot walk along the axis, and once that he reaches the axis he is also in the exact viewpoint (determined by his height). In the other case (parietal) he is free to walk along the axis and so he perceives the painting from different points of view (different distances).

The field of view issues in these two cases assume very different values. These differences can be compared to the ones that occur between the scaled preparation drawing and the real ceiling painting: the scaled drawing can be seen (and usually is) from a greater distance than it was meant to be seen in the real scale (on the vault), and therefore all the distortions are perceptible. For that reason, when the ceiling to depict is very long or low, Pozzo suggested that painters make two preparation-drawings. The first would be the one with the fake observer's distance (greater than the real one, in order to avoid excessive foreshortenings), and that would be the one to be shown to the committee. The other one, that the painter would use secretly, would have the real distances. Once the preparation drawing is 
transposed onto the ceiling all the distortions will disappear because at that point nobody would be able to see it from a greater distance. ${ }^{20}$

On the other hand, in the parietal painting case, the observer has to arrive at the privileged view point and therefore walk all the way along the visual axis. So, his perception of the drawing is motion-conditioned. In such cases, indeed, we can observe very different geometrical solutions. ${ }^{21}$ The projective and geometrical basis of the perspective drawing is in some cases extended with the notion of movement (as far as it is possible within a still picture).

As we have seen in both cases the transpositions of the drawings onto the curved surfaces were done by the aid of developed cartoons. These techniques produced some optical incongruences but neither Melani nor Terreni made efforts to correct them, as suggested by Vignola, because they both were interested more in processes themselves than in the final visual result.

And furthermore, the Terreni brothers consciously made a drawing that does not correspond to any real spatial configuration at all. Aware of the fact that the painting will not be observed from the fixed viewpoint they chose a very ambiguous solution, that provokes a lot of questions. While one walks toward the apse wall, the perception of the depicted space changes constantly. By introducing these temporal and emotional dimensions the artist reveals to us his critical spirit about reality and its representation because the deception the art craft can produce is not enough anymore. This set of operations pertains to the actual scientific culture of the period and, in some manner, the way in which the same problems were faced from different research fields shows a direct relation to the period in which this artefact was conceived. The manner in which particular phenomena do not simply accumulate in history, in the case of the quadraturista that is not interested only in deception but also in the problems related to not developable surfaces (actual cartography issue), shows a potential universality of the human condition.

\section{References}

Bartoli, Maria Teresa and Elena Fossi. 2006. Le tre graticole di Padre Pozzo e il soffitto di Santa Maria Maddalena dei Pazzi a Firenze. In: Quadraturismo e grande decorazione nella pittura di età barocca. Eds. Fauzia Farneti and Deanna Lenzi, 61-75. Firenze: Allinea editrice.

Bartoli, Maria Teresa. 2015. Fuor di regola nelle prospettive del beato angelico. In: Le teorie, le tecniche, i repertori figurativi nella prospettiva d'architettura tra il'400 e il'700. Eds. Maria Teresa Bartoli and Monica Lusoli, 191-202. Firenze: Florence University Press.

De Castro y Velasco, Palomino Antonio (1655-1726). 1795. El museo pictorico, y escala óptica. Madrid. dig. Ed. https://archive.org/details/elmuseopictorico01palo (accessed March 2016).

Galli Bibiena, Ferdinando. 1711. L'architettura civile. Parma.

\footnotetext{
${ }^{20}$ Se volete gabbare la gente semplice, havendo a dipingere opere con la distanza troppo corta, farete due disegni; uno per mostrare a tutti: e in questo il punto di distanza mettete lontano da quello dell'occhio, quanto è necessario per fuggire ogni deformità: del altro disegno servitevene di nascosto nel fare il vostro lavoro (Pozzo 1693).

21 For example we can see the case of palazzo Martelli in Florence (Velluzzi 2015), or the Annunciation by Beato Angelico (Bartoli 2015).
} 
Giannetti, Stefano and Nevena Radojevic. 2011. Sviluppo o proiezione: Dall'affresco del coro dell'abbazia di Vallombrosa, un'indagine sul processo creativo del quadraturismo. In: Abbazia di Vallombrosa-Laboratorio di Rilievo Integrato. Ed. Emma Mandelli, 247-256. Firenze: Allinea editrice.

Mele, Giampiero, Maria Pompeiana Iarossi and Sara Conte. 2015. La prospettiva di sotto in su: palazzo Calderara a Vanzago. In: Le teorie, le tecniche, i repertori figurativi nella prospettiva d'architettura tra il'400 e il'700. Eds. Maria Teresa Bartoli and Monica Lusoli, 295-302. Firenze: Firenze University Press.

Migliari, Riccardo. 2005. Ha la prospettiva un futuro? [Has man a future?]. In: Iknos-Analisi grafica e storia della rappresentazione. Siracusa: Lombardi editori.

Pozzo, Andrea. 1693. Perspectiva pictorum et architectorum. Roma.

Radojevic, Nevena. 2015. La prospettiva solida su una volta a padiglione con pianta trapezia, partendo da un bozzetto piano. Chiesa di San Matteo a Pisa. In: Le teorie, le tecniche, i repertori figurativi nella prospettiva d'architettura tra il'400 e il'700. Eds. Maria Teresa Bartoli and Monica Lusoli, 232-244. Firenze: Florence University Press.

Radojevic, Nevena. 2011. La quadratura di Ognissanti. Concezione dello spazio tra Barocco e Illuminismo. In: Dal Gotico oltre la maniera_gli architetti di Ognissanti a Firenze. Ed. Maria Teresa Bartoli, 49-59. Firenze: Edifir.

Sorte, Christoforo. 1580. Osservazioni nella pittura di M. Christoforo Sorte al Magnifico et Eccellente Dottore et Cavaliere il Signor Bartolomeo Vitali, con privilegio. Dig. Ed. Fondazione Memofonte, 2007, http://www.memofonte.it/trattati/cristoforo-sorte-1510-1595.html (accessed February 2015).

Troili, Giulio. 1672. Paradossi per praticare la prospettiva senza saperla, fiori, per facilitare l'intelligenza, frutti per non operare alla cieca. Bologna: Longhi.

Velluzzi, Nicola. 2015. Prospettiva scenografica: Un esempio a Firenze. In: Le teorie, le tecniche, i repertori figurativi nella prospettiva d'architettura tra il'400 e il'700. Eds. Maria Teresa Bartoli and Monica Lusoli, 275-282. Firenze: Florence University Press.

Vignola, Giacomo Barozzi. 1583. Le due regole della prospettiva pratica di M. Iacomo da Barozzi Vignola con i commentarij del R.P.M. Egnatio Danti .... Roma: Francesco Zanetti. dig. Ed. https:// archive.org/details/dveregoledellapr00vign (accessed March 2016).

Nevena Radojevic is assistant professor of Descriptive Geometry at The University of Ferrara and member of the national research group in Architectural Perspective (PRIN 2011) within the Tuscany unit (prof. Maria Teresa Bartoli's research group). She received her M.A. degree from the Faculty of Architecture in Belgrade and her $\mathrm{PhD}$ from the University of Florence. In her thesis, entitled " $L a$ proiezione centrale nel pensiero scientifico. Dal Pantheon alla Cappella Pazzi" she showed in which manner the central projection was used as a very powerful tool, both at the design (in the case of the Pantheon's dome) and the building execution phase levels (in the case of the Pazzi Chapel in the Church of Santa Croce in Florence designed by Brunelleschi). Her current research interests include examining some particular applications of the central projection principles in architecture (from illusionistic paintings to domes). 